\title{
Acute Tolerability of Methylphenidate in Treatment-Naïve Children with ADHD: An Analysis of Naturalistically Collected Data from Clinical Practice
}

\author{
Gabriele Masi ${ }^{1}$. Chiara Pfanner ${ }^{1}$. Francesca Liboni ${ }^{1}$. Francesca Lenzi ${ }^{1}$ - Arianna Villafranca ${ }^{1}$. Giulia D'Acunto ${ }^{1}$. \\ Pamela Fantozzi ${ }^{1}$. Francesca Falcone ${ }^{2}$. Valerio Simonelli ${ }^{2}$. Pietro Muratori ${ }^{1}$ - Valentina Levantini ${ }^{1}$ - Irene Favole ${ }^{3}$. \\ Federico Amianto ${ }^{4} \cdot$ Chiara Davico $^{3} \cdot$ Benedetto Vitiello $^{3}$ (1)
}

Accepted: 10 January 2022 / Published online: 9 February 2022

(c) The Author(s) 2022

\begin{abstract}
Objectives The acute tolerability of methylphenidate (MPH) in children with attention-deficit/hyperactivity disorder (ADHD) has been studied mainly in research samples. Taking advantage of the mandatory test-dose procedure required for starting MPH in Italy, this study aimed to assess the incidence of intolerable adverse events after initial exposure to MPH in routine clinical practice.

Methods The medical records of 480 consecutively treated, previously drug-naïve children and adolescents with ADHD (90\% male, mean age $10.6 \pm 3.0$ years) were retrospectively analyzed. All children received an initial single dose of MPH immediate release $(5 \mathrm{or} 10 \mathrm{mg}$ ) followed by a 4-hour direct medical observation. Heart rate and blood pressure were measured at dosing and 1,2, and 3 hours afterwards. If the first dose was well tolerated, the child continued treatment with MPH 5-20 mg daily, and was reassessed a week later.

Results Eleven patients $(2.3 \%, 95 \%$ CI 1.1-4.1) interrupted treatment within a week of initiation because of the following adverse events: irritability $(n=3)$, tics worsening $(n=3)$, reduced appetite $(n=1)$, enuresis $(n=1)$, hallucinations $(n=1)$, hyperfocus $(n=1)$, and 'rebound' behavioral worsening $(n=1)$. The most common adverse events were reduced appetite $(20 \%)$, irritability $(14.2 \%)$, headache $(10.6 \%)$, sleep problems $(9.4 \%)$, stomachache $(9.4 \%)$, and tics $(5 \%)$. Intellectual disability increased the risk of any adverse event in general and of irritability in particular. No cardiovascular symptom was clinically reported. However, routine assessments of vital signs during the first 3 hours after the first dose of MPH showed that $9 \%$ of the children had a $20 \%$ increase in heart rate, $8.8 \%$ had a $20 \%$ increase in diastolic blood pressure and $4.5 \%$ had a 20\% increase in systolic blood pressure. Of these, $25.2 \%$ still had an elevated heart rate 1 week later.

Conclusions Among stimulant-naïve children in clinical practice, the incidence of acute MPH intolerance can be estimated to be between 1.2 and $4.1 \%$. An asymptomatic elevation in cardiovascular parameters can be observed in about 1 out of 10 children and warrants monitoring during ongoing treatment.
\end{abstract}

Benedetto Vitiello

benedetto.vitiello@unito.it

1 IRCCS Stella Maris, Scientific Institute of Child Neurology

and Psychiatry, Calambrone, Pisa, Italy

2 Department of Clinical and Experimental Medicine,

University of Pisa, Pisa, Italy

3 Section of Child and Adolescent Neuropsychiatry, Department of Public Health and Pediatric Sciences, University of Turin, Turin, Italy

4 Department of Neurosciences, University of Turin, Turin, Italy 


\section{Key Points}

Based on this study, it can be estimated that between 1.2 and $4.1 \%$ of school-age children with attention-deficit/ hyperactivity disorder (ADHD) starting methylphenidate (MPH) will interrupt the medication within a week due to the emergence of some adverse event.

Children with intellectual disability were at greater risk of developing adverse events, in particular irritability, when starting MPH.

Compared with pre-treatment values, about 1 in 10 children had a $20 \%$ or greater increase in heart rate and/or blood pressure that was asymptomatic but persisted with time in 1 out of 4 cases.

\section{Introduction}

The incidence of intolerable or prohibitive adverse events upon starting a treatment, defined as the emergence of signs or symptoms that cause treatment to be discontinued, can be taken as an index of acute intolerance [1]. Methylphenidate (MPH) is commonly prescribed to treat children with attention-deficit/hyperactivity disorder (ADHD), and its safety profile has been thoroughly investigated in numerous controlled and observational studies [2, 3]. Commonly reported adverse events are decreased appetite, sleep disturbance, stomachache, and headache, while less frequent is the emergence or worsening of tics. In most cases, adverse events can be managed without interrupting treatment and tend to abate with continuous administration of the medication $[1,4,5]$.

Less well documented, however, is the rate of intolerable adverse events that lead to treatment discontinuation in usual clinical practice. Available estimates of lack of tolerability to initial exposure to MPH are mainly derived from clinical trials or other research samples rather than usual practice. A $1.4 \%$ rate of intolerable adverse events was reported in the open-label lead-in of the Multimodal Treatment Study of ADHD (MTA), which included 289 children aged 7-9 years, of whom four had prohibitive adverse events (buccal movements; skin picking; tearfulness, appetite loss and sleep delay; and listlessness, emotional blunting, and anorexia) [6]. Higher rates of intolerable adverse events have been reported in children with ADHD in the context of autism spectrum disorder (ASD) [8\%] and in preschoolers with ADHD (6\%), mostly due to emotional outbursts and irritability $[7,8]$. These estimates were based on research samples, which, being selected according to rather stringent inclusion and exclusion criteria, are not necessarily representative of the usual clinical population. In addition, participants in research studies are not necessarily drug-naïve, and this selection bias can affect estimates of tolerability.

More recently, a meta-analysis of non-randomized studies found an MPH discontinuation rate of $1.2 \%$ for serious adverse events and of $7.3 \%$ for adverse events of unknown severity, but with a low quality of evidence that made it impossible to make accurate estimates [9]. It should also be noted that this meta-analysis is prone to a possible bias, as it included observational studies without taking into account putative confounders.

In Italy, no medication for ADHD had been available until 2007, when the Italian Drug Regulatory Agency granted market authorization for immediate-release MPH (IR-MPH) and atomoxetine for children and adolescents (6-18 years old) on the condition that patients be enrolled into a dedicated national registry with standard operative procedures (SOP) for accessing medications [10]. This registry has been previously analyzed to compare MPH and atomoxetine safety [11]. As part of the SOP for starting MPH treatment, children must receive the first dose of MPH in a controlled clinical setting with monitoring for the first few hours after administration to detect possible adverse events, including repeated measuring of resting heart rate (HR) and systolic (sBP) and diastolic blood pressure (dBP). These assessments are to be repeated after 1 week of treatment. The data from this mandatory first-dose test could help estimate the incidence of intolerable adverse events after initial exposure to MPH in usual clinical practice.

The aim of this study was to assess the acute tolerability to initial exposure to MPH among treatment-naïve children with ADHD in usual clinical practice, with special attention to possible changes in $\mathrm{HR}$, sBP, or dBP. Possible predictors of the most common adverse events (i.e., anxiety, irritability, reduced appetite, and sleep disruption) were explored.

\section{Methods}

\subsection{Design and Procedure}

This was a retrospective analysis of clinical records collected at two ADHD clinics (University of Pisa and University of Turin) as part of the Italian ADHD National Registry. All patients had been clinically referred and received the assessments required by the Italian medicine regulatory agency to be treated with MPH. Parents were informed of the procedures and risks and potential benefits of MPH, and gave written informed consent for their child to be assessed and treated and for the data to be included in the ADHD National Registry. Assent was obtained also from the child 
when appropriate based on developmental stage and cognitive functioning.

\subsection{Sample}

All children (aged 6-18 years) consecutively referred in the years 2017-2020 for initiating pharmacological treatment of ADHD with MPH were included. These patients had been clinically diagnosed with ADHD according to DSM-5 criteria by trained child psychiatrists, and assessed with specific validated questionnaires (i.e., ADHD-Rating Scales or Conners Parent and Teacher ADHD Rating Scales). At the University of Pisa site, a semi-structured clinical interview, the Kiddie-SADS-PL, was also part of the clinical evaluation. Comorbidities with oppositional defiant disorder or conduct disorder (ODD/CD), mood disorder, anxiety disorder, ASD, and intellectual disability (ID) were identified. As appropriate, intellectual functioning was assessed with the Wechsler intelligence scales. Prior to initiating treatment, all patients received a physical examination to exclude treatment-relevant medical conditions and a standard 12-lead electrocardiogram (ECG) to exclude conduction abnormalities.

\subsection{Methylphenidate Treatment}

All patients were stimulant-naïve at intake. On the first day, an initial single dose of MPH $5 \mathrm{mg}$ or $10 \mathrm{mg}$ was given orally at the clinics in the morning. The dosage was based on age and weight $(5 \mathrm{mg}$ for children younger than 10 years or below $30 \mathrm{~kg}$, and $10 \mathrm{mg}$ in the older or heavier children) and parental preference. Based on these criteria, 209 (43.5\%) received $5 \mathrm{mg}$, and $271(56.5 \%)$ received $10 \mathrm{mg}$. If tolerability to the first dose was satisfactory, MPH was continued at the initial dose once or twice daily, based on clinical needs, and the child was reassessed after about a week (range 7-9 days).

\subsection{Safety Assessments}

On the morning of the first test dose of MPH, resting HR and $\mathrm{SBP}$ and $\mathrm{dBP}$ were measured after the child had been sitting for at least 5 minutes, by nurses using an automatic digital blood pressure arm monitor, immediately before receiving the MPH dose, and 1, 2, and 3 hours afterward. Only one reading was recorded for each measurement, but values considered abnormal (i.e., for children aged 6-11 years: $\mathrm{HR}>110 \mathrm{bpm}$, or $\mathrm{sBP}$ or $\mathrm{dBP}>95^{\text {th }}$ percentile for age; for older youth: $\mathrm{HR}>100 \mathrm{bpm}, \mathrm{sBP}>120 \mathrm{mmHg}$, or $\mathrm{dBP}>80 \mathrm{mmHg}$ ) were re-checked, and MPH treatment was continued only if the parameters were within the normal range.

Spontaneously reported adverse events were collected up to 4 hours after the first MPH administration. After about 1 week, safety assessments were repeated. The child psychiatrist inquired with the child and their family about possible emergence in the past week of any adverse event known to be associated with stimulant medications (decreased appetite, insomnia, gastrointestinal symptoms, headache, tics, mood changes), and collected any other spontaneously reported adverse events.

\subsection{Statistical Analyses}

The data were analyzed with IBM SPSS Statistics 23. First, we imputed missing data (5.5\% of the data were incomplete) using multiple imputations, under fully conditional specification, using the default setting "Impute Missing Data Values (Multiple Imputation)" available on SPSS 23.

As a preliminary analysis, we compared the patients enrolled at the Pisa center with those enrolled in Turin. There were no significant differences with respect to patients' age, gender, and main comorbidities, except for ID which was more prevalent in the Turin sample $(\chi 2=31.52$; $p<0.001)$. Descriptive statistics were applied to the data. We analyzed categorical variables using chi-square analysis, and continuous variables with univariate analyses of variance (ANOVA). We compared the following groups: patients receiving $5 \mathrm{mg}$ versus $10 \mathrm{mg}$ of MPH during the first week of treatment, subjects showing versus not showing irritability, reduced appetite, or sleep problems after a week of MPH administration. We explored possible age, gender, or comorbidity effect on $\mathrm{HR}, \mathrm{sBP}$, and $\mathrm{dBP}$ at baseline $\left(T_{0}\right)$, and $1\left(T_{1}\right), 2\left(T_{2}\right)$, and 3 hours $\left(T_{3}\right)$ after the first dose of MPH. At the individual level, differences in cardiovascular parameters were considered clinically significant if deviated by more than $20 \%$ from the baseline. At the group level, differences were considered statistically significant if $p<0.05$.

One-way repeated measures ANOVA was used to test whether HR, sBP, and dBP significantly changed over time. As the sphericity assumption was violated (Mauchly's test: $p<0.05)$, we used Huynh-Feldt estimates [12, 13]. Pairwise comparisons with Bonferroni adjustment for multiple comparisons were conducted. To explore for possible predictors of acute intolerability to MPH, multivariate logistic analyses were performed using presence of adverse events as the dependent variable, and age, sex, dose $(5$ or $10 \mathrm{mg})$, ASD, ID, and ODD/CD as independent variables. The Hosmer-Lemeshow test was used to test the goodness-of-fit of the models.

\section{Results}

\subsection{Sample Characteristics}

The sample consisted of 480 children and adolescents (456 at Pisa and 24 at Turin), comprising $90.4 \%$ males, aged 
6-18 years (mean age $10.6 \pm 3.0)$, with ADHD $(92.5 \%$ with hyperactive/combined type and $7.5 \%$ with inattentive presentation) (Table1). There was comorbidity with ODD/CD $(n=120,25 \%)$, mood disorders $(n=61,12.7 \%)$, anxiety disorders $(n=42,8.7 \%)$, ASD $(n=31,6.5 \%)$, tic disorder $(n=17,3.5 \%)$, and ID $(n=37,7.7 \%)$.

\subsection{Tolerability to the Initial Test Dose of MPH}

Less than $2 \%$ of the children had a clinically reported adverse event in the 4 hours after the first MPH dose while the patients were under direct medical observation at the clinic (Table 2). The most common adverse events were headache $(1.9 \%)$, irritability (1.3\%), and tics $(1.3 \%)$. No reported adverse event was deemed a reason for not continuing MPH treatment. One child who received an initial dose of MPH $10 \mathrm{mg}$ presented with sustained tachycardia (>130 bpm) 3 hours after administration, without any accompanying subjective complaints, or clinically observable symptoms, and with return to normal HR values after 4 hours. MPH treatment was discontinued. A few weeks later, the child was tested with a 5-mg dose and monitored for 3 $\mathrm{h}$ without presenting tachycardia. He continued treatment with this lower dose without any adverse events. No cases of persistent tachycardia or hypertension were observed.

$\mathrm{HR}, \mathrm{sBP}$, and dBP recordings at baseline, $1 \mathrm{~h}, 2 \mathrm{~h}$, and 3 $\mathrm{h}$ after the first MPH administration are reported in Table 3 . As expected, age was negatively correlated with HR (at baseline, $r=-0.36 ; p<0.001$ ), and positively correlated with sBP $(r=0.43 ; p<0.001)$ and $\mathrm{dBP}(r=0.23$; $p<0.001)$. There was a statistically significant time effect on HR $\left(F=22.4 ; p<0.001, \eta_{\mathrm{p}}^{2}=0.045\right)$. Pairwise comparisons showed that baseline HR was significantly lower that $\mathrm{HR}$ at $T_{1}$ (mean difference $-2.7 ; p<0.001$ ), $T_{2}$ (mean difference $-3.9 ; p<0.001$ ), and $T_{3}$ (mean difference -2.7 ;

Table 1 Demographics and clinical characteristics

\begin{tabular}{lc}
\hline & $N=480$ \\
\hline Male sex $(N, \%)$ & $434(90.4)$ \\
Age, years, mean $(\mathrm{SD})$ & $10.6(3.0)$ \\
ADHD $(N, \%)$ & \\
Hyperactive/combined & $444(92.5)$ \\
Inattentive & $36(7.5)$ \\
ODD/CD $(N, \%)$ & $120(25.0)$ \\
Mood disorder $(N, \%)$ & $61(12.7)$ \\
Anxiety disorder $(N, \%)$ & $42(8.7)$ \\
ASD $(N, \%)$ & $31(6.5)$ \\
Intellectual disability $(N, \%)$ & $37(7.7)$ \\
Tic disorder $(N, \%)$ & $17(3.5)$ \\
\hline
\end{tabular}

$A D H D$ attention-deficit/hyperactivity disorder, $A S D$ autism spectrum disorder, $O D D / C D$ oppositional defiant disorder/conduct disorder
Table 2 Clinically reported adverse effects during the first $4 \mathrm{~h}$ and after 1 week of methylphenidate treatment (sample $N=480$ )

\begin{tabular}{lll}
\hline Adverse effect, $n(\%)$ & After 4 h & After 1 week \\
\hline Irritability & $6(1.3)$ & $68(14.2)$ \\
Reduced appetite & 0 & $98(20.0)$ \\
Headache & $9(1.9)$ & $51(10.6)$ \\
Sleep problems & 0 & $45(9.4)$ \\
Gastrointestinal symptoms & $3(0.6)$ & $37(7.7)$ \\
Anxiety symptoms & $1(0.2)$ & $27(5.6)$ \\
Tics & $6(1.3)$ & $24(5.0)$ \\
Tachycardia (> 130 bpm) & $1(0.2)$ & 0 \\
Hyperphagia & 0 & $15(3.1)$ \\
Enuresis & 0 & $14(2.9)$ \\
Obsessive-compulsive disorder symptoms & 0 & $13(2.7)$ \\
Mood symptoms & 0 & $15(3.1)$ \\
Fatigue & 0 & $12(2.5)$ \\
Hallucinations & 0 & $1(0.2)$ \\
Hyperfocus & 0 & $9(1.9)$ \\
Behavioral worsening ('rebound') & 0 & $16(3.3)$ \\
\hline
\end{tabular}

${ }^{\mathrm{a}}$ Worsening of behavioral symptoms about $5 \mathrm{~h}$ after the last methylphenidate dose

Table 3 Resting heart rate, and diastolic and systolic blood pressure at baseline and during the first $3 \mathrm{~h}$ after methylphenidate (MPH) administration

\begin{tabular}{|c|c|c|c|c|}
\hline & Min & Max & Mean & SD \\
\hline \multicolumn{5}{|c|}{ HR (bpm)*** } \\
\hline$T_{0}$ & 49 & 149 & 79.6 & 14.2 \\
\hline$T_{1}$ & 49 & 126 & 82.3 & 14.2 \\
\hline$T_{2}$ & 50 & 140 & 83.5 & 15.1 \\
\hline$T_{3}$ & 51 & 141 & 82.3 & 15.2 \\
\hline \multicolumn{5}{|c|}{ sBP (mmHg) } \\
\hline$T_{0}$ & 60 & 171 & 109.3 & 13.6 \\
\hline$T_{1}$ & 40 & 204 & 110.3 & 14.0 \\
\hline$T_{2}$ & 75 & 144 & 110.1 & 12.1 \\
\hline$T_{3}$ & 71 & 154 & 110.0 & 11.9 \\
\hline \multicolumn{5}{|c|}{$\mathrm{dBP}(\mathrm{mmHg}) * * *$} \\
\hline$T_{0}$ & 38 & 99 & 66.2 & 9.2 \\
\hline$T_{1}$ & 40 & 109 & 66.7 & 9.3 \\
\hline$T_{2}$ & 43 & 110 & 68.1 & 9.3 \\
\hline$T_{3}$ & 46 & 89 & 68.0 & 8.0 \\
\hline
\end{tabular}

$T_{0}$ : at baseline, just before the MPH first dose; $T_{1}, T_{2}, T_{3}: 1,2$, and 3 $\mathrm{h}$, respectively, after the MPH dose

$N=467$ for $\mathrm{HR}$ and $\mathrm{dBP}$, and $N=464$ for sBP

$d B P$ diastolic blood pressure, $H R$ heart rate, Max maximum, Min minimum, $s B P$ systolic blood pressure, $S D$ standard deviation

***Statistically significant increase in HR and dBP (time effect $p<0.001)$ 
$p<0.001)$. There was also a statistically significant time effect on $\mathrm{dBP}\left(F=9.1 ; p<0.001, \eta_{\mathrm{p}}^{2}=0.019\right)$. Pairwise comparisons showed that baseline $\mathrm{dBP}$ was significantly lower that HR at $T_{2}$ (mean difference $-19.9 ; p=0.001$ ), and $T_{3}$ (mean difference $-1.8 ; p<0.001$ ). Also, dBP at $T_{1}$ were significantly lower than $\mathrm{dBP}$ at $T_{2}$ (mean difference -1.4 ; $p=0.013$ ) and $\mathrm{T}_{3}$ (mean difference $-1.3 ; p=0.016$ ). No statistically significant time effect on $\mathrm{SBP}$ was found $\left(F=0.95 ; p=0.411, \eta_{\mathrm{p}}^{2}=0.002\right)$.

During the first $3 \mathrm{~h}$ after the first dose, after excluding those with missing data (13 for HR and dBP, and 16 for sBP), 42 children (9.0\%) presented an increase in HR $>20 \%$ from the baseline; $41(8.8 \%)$ had an increase in $\mathrm{dBP}>20 \%$, and $21(4.5 \%)$ had an increase in sBP $>20 \%$. Three patients $(0.6 \%)$ presented an increase $>20 \%$ in both $\mathrm{dBP}$ and $\mathrm{sBP}$, eight patients in both HR and sBP, and five patients in both HR and dBP.

\subsection{Tolerability During the First Week of Treatment}

Eleven patients $(2.3 \%, 95 \%$ CI 1.1-4.1) interrupted MPH treatment within the first week due to adverse events: three for irritability, three for worsening tics, one for reduced appetite, one for enuresis, one for transient auditory hallucinations, one for being hyperfocused, and one for marked behavioral worsening at the end of the MPH pharmacological effect ('rebound').

During the first week of treatment, the most reported adverse events were reduced appetite (20.0\%), irritability $(14.2 \%)$, headache (10.6\%), sleep problems $(9.4 \%)$, and gastrointestinal symptoms (7.7\%) (Table 2). In $5 \%$ of the children there was onset or worsening of tics.

Children who presented irritability $(n=68,14.2 \%)$ were on average younger than those without irritability ( 9.5 years $\pm \mathrm{SD} 2.6$ vs 12.6 years $\pm \mathrm{SD} 3.0, F=10.8 ; p=0.001)$, and had a higher rate of comorbid ID $(17.6 \%$ vs $6.1 \%$, $\left.\chi^{2}(2)=11.0 ; p=0.001\right)$.

Multivariate logistic analyses indicated that occurrence of any adverse event during the first week of treatment was predicted by ID $(B=0.828$, S.E. $=0.368$, Wald $=5.068, p=0.024, \operatorname{Exp}(B)=2.289)$, but not by any of the other tested variables (age, sex, dose, ASD, or ODD/CD). Reduced appetite was predicted by ODD/CD $(B=0.538$, S.E. $=0.250$, Wald $=4.635, p=0.031, \operatorname{Exp}(B)=1.712$ ); irritability by $\operatorname{ID}(B=1.104$, S.E. $=0.396$ Wald $=7.764, p$ $=0.005, \operatorname{Exp}(B)=3.016)$ and higher MPH dose $(B=0.760$, S.E. $=0.310$, Wald $=6.016, p=0.014, \operatorname{Exp}(B)=2.138$ ); and sleep disturbance by ID $(B=1.139$, S.E. $=0.447$, Wald $=6.487, p=0.011, \operatorname{Exp}(B)=3.125)$ and $\mathrm{ODD} / \mathrm{CD}(B=$ 0.786 , S.E. $=0.339$, Wald $=5.367, p=0.024, \operatorname{Exp}(B)=$ 2.195).
After 1 week of treatment, $86(18.4 \%)$ of the children presented an increase of $20 \%$ or more in HR over the pretreatment baseline; 61 (13.4\%) presented a similar increase in $\mathrm{SBP}$ and $51(11.2 \%)$ in dBP. In particular, $25.2 \%$ of the children with $20 \%$ or more HR elevation after the first dose $(n=42)$, still had $>20 \%$ elevated HR after a week.

\section{Discussion}

This study assessed the acute tolerability of MPH in stimulant-naïve children who received the first test dose of MPH as part of the required procedures for pharmacological treatment of ADHD in Italy. The large sample size and the inclusion of consecutively treated children who were referred for clinical rather than research purposes allow the incidence of intolerable adverse events to be estimated with adequate statistical precision in a clinically representative sample. Considering the observed incidence of $2.3 \%$ and $95 \% \mathrm{CI}$, it can be inferred that intolerance to MPH (i.e., discontinuation due to an adverse event within a week of starting treatment) occurs in between 1.2 and $4.1 \%$ of children first exposed to MPH. This rate is consistent with the $1.4 \%$ reported in the MTA study [6].

The adverse events that were reported, including those leading to MPH discontinuation, were generally part of the known safety profile of stimulant medications. After the first dose, $1.9 \%$ of the children developed headache, $1.3 \%$ presented with irritability and $1.3 \%$ with tics. Thus, the occurrence of any clinically important adverse event in the first week after starting MPH treatment can be considered infrequent and, in most cases, not a reason for discontinuation. The data confirm that psychotic symptoms (hallucinations), which were reported in one patient $(0.2 \%)$, are rare and transient in MPH treatment $[2,14]$. It can also be estimated that about $5 \%$ of children will present with onset or worsening of existing tics upon initial exposure to MPH, but, in most cases, this does not cause treatment discontinuation. This finding is consistent with existing literature on tics and stimulant medications [15]. A small number of children (14 or $2.9 \%$ ) reported enuresis, which is not an adverse event typically associated with stimulant treatment, even though it has been anecdotally reported [16, 17].

The rates of common adverse events such as decreased appetite, sleep disturbance, headache, or stomachache were lower than reported in randomized placebo-controlled trials [4]. For example, based on a meta-analysis of 62 clinical trials, insomnia occurred in $42.1-53.3 \%$ of children randomized to MPH, as compared with $23.9-37.5 \%$ of those on placebo, and stomachache incidence was $19.0-28.9 \%$ on MPH versus $8.7-21.1 \%$ on placebo [4]. The discrepancy with the rates found in our study can be accounted for by the systematic elicitation of adverse events in controlled clinical 
trials, which yields high rates of mild symptoms that are not necessarily clinically significant or due to the medication, as shown by the high rate of adverse events on placebo (a possible 'nocebo' effect). In fact, in the same meta-analysis, the rates of 'serious' adverse events (e.g., 10.9\% for insomnia and $5.2 \%$ for stomachache) was close to those found in our database (i.e., 9.4\% for sleep problems and 7.7\% for gastrointestinal symptoms). Another possible contributor to the lower rate of adverse events in this study is the low doses of MPH administered in the initial week of treatment, while in clinical trials, dosage is usually increased more rapidly to reach full therapeutic levels. In fact, MPH-induced adverse events are typically dose-dependent, as also shown by the higher rate of irritability on $10 \mathrm{mg}$ as compared with $5 \mathrm{mg}$ in our study.

Presence of ID, but not ASD per se, was a risk factor for presenting with any adverse event and, in particular, with irritability. These findings are consistent with the higher rate of treatment-emergent irritability observed in a randomized trial of MPH in a sample of children with ASD and mean IQ of 62.6 [7]. Our data suggest that it is ID, as an index of severe neurodevelopmental disorder, and not ASD that is linked with a lower tolerability to MPH $[18,19]$.

No cardiovascular symptoms, such as palpitations or dizziness, were clinically reported in this sample. However, routine assessments of vital signs during the first 3 hours of treatment and 1 week later revealed an increase in HR, sBP, and dBP (Table 3). These data confirm that MPH treatment is in general associated with small, although statistically significant, increases in $\mathrm{HR}, \mathrm{sBP}$, and $\mathrm{dBP}$, although without clinical implications in most cases [1, 20-22]. In reviewing available data, Hammerness et al. found that MPH treatment was associated with mean elevations of $5 \mathrm{mmHg}$ in blood pressure and $10 \mathrm{bpm}$ in HR [23]. A more recent review reported that MPH was linked with elevation in $\mathrm{sBP}$ only, but not in dBP or HR [24]. In our study, by selecting a priori a $20 \%$ or greater increase over the pre-treatment baseline, we attempted to estimate the incidence of more evident effects on cardiovascular function. We found that about one in ten children had a $20 \%$ or greater increase in $\mathrm{HR}, \mathrm{sBP}$, or $\mathrm{dBP}$ in the $3 \mathrm{~h}$ following the initial dose, and that about one in five had a similar increase after 1 week of treatment. These data indicate a lack of tolerance to the cardiovascular effects of MPH, at least in the short-term, and are consistent with the conclusions of previous reports $[1,16]$. One patient $(0.2 \%)$ had sustained tachycardia, without subjectively reported palpitations, in the first 3 hours after first MPH dosing with $10 \mathrm{mg}$. The tachycardia later resolved, and the child was rechallenged with a 5-mg dose on a subsequent day without emergence of tachycardia. It should be noted that all children in this sample had documented normal ECG prior to treatment. This case indicates that clinically significant, although asymptomatic, elevation in cardiovascular parameters, though rare and transient, can occur upon starting stimulant medication. The importance of monitoring HR and blood pressure during early phases of MPH treatment is reaffirmed by these data.

The study has several limitations that should be considered in interpreting the results. The data were collected as part of the clinical management of children with ADHD in Italy, rather than for research purposes. Assessment of adverse events relied on clinical observation and reports from patients and parents rather than on a structured and systematic inquiry of possible health. The cardiovascular measurements were done by nurses or physicians using standard equipment but without following research procedures (e.g., there was no averaging of three consecutive readings of HR and blood pressure). MPH was administered in an immediate-release formulation (as required by the Italian register regulations), while extended-release preparations are more commonly used in chronic treatment, and the formulation of stimulant medication can have implications for adverse events [25]. The dose of MPH (5 mg or $10 \mathrm{mg}$ ) can be considered a starting dose, to be then gradually adjusted based on clinical needs. As adverse effects to stimulants are doserelated, it is possible that a greater rate of adverse events would have emerged with higher doses. Furthermore, the period of observation was limited to the initial few weeks of treatment. Finally, the generalizability of the results is limited because this was not a population-based study, and the data came from only two clinics. These limitations must be considered in the light of the strengths of the study, including the clinically representative sample of children with ADHD and typical comorbidity, the large sample size, and the direct medical observation for several hours after the first dose. In addition, the fact that all children were drug-naïve at intake prevented the exclusion of participants with previous intolerable adverse events, which constitutes a common selection bias in clinical trial samples.

\section{Conclusions}

The results from this study indicate that intolerance to acute administration of starting doses of MPH is infrequent and can be estimated to be between 1.2 and $4.1 \%$ within 1 week of treatment. The results confirm the safety profile of MPH with irritability, headache, reduction in appetite, and sleep problems being the most common adverse events, reported in $>10 \%$ of the sample. The study also further documents the cardiovascular stimulating effects of MPH, which warrant monitoring of HR and blood pressure during the medication management follow-up visits. 


\section{Declarations}

Funding Italian Ministry of Health: Ricerca Corrente (Gabriele Masi, Project 2.02: Attention-Deficit/ Hyperactivity Disorder (ADHD): Phenotypic Specifiers and Treatment Implications), and public voluntary contributions under the program " 5 per 1000".

Conflicts of interest/Competing interests In the last 2 years, GM was a member of advisory boards for Angelini Pharmaceuticals, received institutional grants from Lundbeck and Humana, and was a speaker for Angelini, FB Health, Janssen, Lundbeck, and Otsuka. BV has received consultant fees or honoraria from Medice, Lundbeck, and Angelini Pharmaceuticals, and from law firms Goodwin \& Procter and Haynes $\&$ Boone. The other authors report no biomedical financial interests or potential conflicts of interest.

Consent to participate All the parents signed written informed consent for their child to receive the assessment procedure, the first-dose test, and the subsequent pharmacological treatment, according to the standard operative procedure defined by the Italian Ministry of Health. The protocol (Italian ADHD National Registry) has been approved by the Italian Ministry of Health.

\section{Consent to publication Not applicable.}

Code availability Not applicable.

Author contributions Conceptualization: GM and BV; design and methods: GM, CP and BV; data collection: FL, FL, AV, GD, PF, and IF; data management: FF, VS, PM, and VL; manuscript preparation: GM and BV; review and editing: CP, FL, FL, AV, GD, PF, FF, VS, $\mathrm{PM}$, VL, IF, FA, and CD. All authors approved the published version of the manuscript and agreed to be accountable for the work outlined in the manuscript.

Availability of data and material (data transparency) Study data are available from the authors upon reasonable request.

Ethics The protocol (Italian ADHD registry) has been completed and approved by the Italian Ministry of Health. Anonymized data from registry, with parental consent to inclusion.

Open Access This article is licensed under a Creative Commons Attribution-NonCommercial 4.0 International License, which permits any non-commercial use, sharing, adaptation, distribution and reproduction in any medium or format, as long as you give appropriate credit to the original author(s) and the source, provide a link to the Creative Commons licence, and indicate if changes were made. The images or other third party material in this article are included in the article's Creative Commons licence, unless indicated otherwise in a credit line to the material. If material is not included in the article's Creative Commons licence and your intended use is not permitted by statutory regulation or exceeds the permitted use, you will need to obtain permission directly from the copyright holder. To view a copy of this licence, visit http://creativecommons.org/licenses/by-nc/4.0/.

\section{References}

1. Cortese S, Holtmann M, Banaschewski T, Buitelaar J, Coghill D, Danckaerts M, Dittmann RW, Graham J, Taylor E, Sergeant J, European ADHD Guidelines Group. Practitioner review: current best practice in the management of adverse events during treatment with ADHD medications in children and adolescents. J Child Psychol Psychiatry. 2013;54(3):227-46. https://doi.org/10. 1111/jcpp.12036.

2. Cortese S, Adamo N, Del Giovane C, Mohr-Jensen C, Hayes AJ, Carucci S, Atkinson LZ, Tessari L, Banaschewski T, Coghill D, Hollis C, Simonoff E, Zuddas A, Barbui C, Purgato M, Steinhausen HC, Shokraneh F, Xia J, Cipriani A. Comparative efficacy and tolerability of medications for attention-deficit hyperactivity disorder in children, adolescents, and adults: a systematic review and network meta-analysis. Lancet Psychiatry. 2018;5(9):727-38. https://doi.org/10.1016/S2215-0366(18)30269-4.

3. Cortese S. Pharmacologic treatment of attention deficit-hyperactivity disorder. New Engl J Med. 2020;383(11):1050-6.

4. Schachter HM, Pham B, King J, Langford S, Moher D. How efficacious and safe is short-acting methylphenidate for the treatment of attention-deficit disorder in children and adolescents? A metaanalysis. CMAJ. 2001;165(11):1475-88.

5. Storebø OJ, Krogh HB, Ramstad E, Moreira-Maia CR, Holmskov M, Skoog M, Nilausen TD, Magnusson FL, Zwi M, Gillies D, Rosendal S, Groth C, Rasmussen KB, Gauci D, Kirubakaran R, Forsbøl B, Simonsen E, Gluud C. Methylphenidate for attention-deficit/hyperactivity disorder in children and adolescents: Cochrane systematic review with meta-analyses and trial sequential analyses of randomised clinical trials. BMJ. 2015;25(351): h5203. https://doi.org/10.1136/bmj.h5203.

6. Greenhill LL, Swanson JM, Vitiello B, Davies M, Clevenger W, Wu M, Arnold LE, Abikoff HB, Bukstein OG, Conners CK, Elliott GR, Hechtman L, Hinshaw SP, Hoza B, Jensen PS, Kraemer HC, March JS, Newcorn JH, Severe JB, Wells K. WigalT: impairment and deportment responses to different methylphenidate doses in children with ADHD: the MTA titration trial. J Am Acad Child Adolesc Psychiatry. 2001;40:180-7.

7. Research Units on Pediatric Psychopharmacology (RUPP). Autism Network: a randomized controlled crossover trial of methylphenidate in pervasive developmental disorders with hyperactivity. Arch Gen Psychiatry. 2005;62:1266-74.

8. Wigal T, Greenhill LL, Chuang S, McGough JJ, Vitiello B, Skrobala AM, Swanson J, Wigal S, Abikoff H, Kollins SH, McCracken JT, Riddle M, Posner K, Ghuman JK, Davies M, Thorp B, Stehli A. Safety and tolerability of methylphenidate in preschool children with ADHD. J Am Acad Child Adolesc Psychiatry. 2006;45:1294-303.

9. Storebø OJ, Pedersen N, Ramstad E, Kielsholm ML, Nielsen SS, Krogh HB, Moreira-Maia CR, Magnusson FL, Holmskov M, Gerner T, Skoog M, Rosendal S, Groth C, Gillies D, Buch Rasmussen K, Gauci D, Zwi M, Kirubakaran R, Håkonsen SJ, Aagaard L, Simonsen E, Gluud C. Methylphenidate for attention deficit hyperactivity disorder (ADHD) in children and adolescents - assessment of adverse events in non-randomised studies. Cochrane Database Syst Rev. 2018;5(5): CD012069. https://doi. org/10.1002/14651858.CD012069.pub2.

10. Panei P, Arcieri R, Vella S, Bonati M, Martini N, Zuddas A. Italian attention-deficit/hyperactivity disorder registry. Pediatrics. 2004;114(2):514. https://doi.org/10.1542/peds.114.2.514.

11. Cortese S, Panei P, Arcieri R, Germinario EA, Capuano A, Margari L, Chiarotti F, Curatolo P. Safety of methylphenidate and atomoxetine in children with attention-deficit/hyperactivity disorder (ADHD): data from the Italian National ADHD Registry. CNS Drugs. 2015;29(10):865-77. https://doi.org/10.1007/ s40263-015-0266-7.

12. Barcikowski RS, Robey RR. Decisions in single group repeated measures analysis: statistical tests and three computer packages. Am Stat. 1984;1984(38):148-50.

13. Huynh H, Feldt LS. Estimation of the Box correction for degrees of freedom from sample data in randomized block and split-plot designs. J Ed Stat. 1976;1:69-82. 
14. Cortese S. Psychosis during attention deficit-hyperactivity disorder treatment with stimulants. N Engl J Med. 2019;380(12):117880. https://doi.org/10.1056/NEJMe1900502.

15. Osland ST, Steeves TD, Pringsheim T. Pharmacological treatment for attention deficit hyperactivity disorder (ADHD) in children with comorbid tic disorders. Cochrane Database Syst Rev. 2018;6(6): CD007990. https://doi.org/10.1002/14651858.CD007 990.pub3.

16. Uzun N, Akinci MA, Karatoprak S. Methylphenidate-induced enuresis: 3 case reports. Clin Neuropharmacol. 2021;44(1):37-8. https://doi.org/10.1097/WNF.0000000000000422.

17. Ghanizadeh A. Methylphenidate-associated enuresis in attention deficit hyperactivity disorder. J Pediatr Urol. 2008;4(4):306-7. https://doi.org/10.1016/j.jpurol.2007.10.001.

18. Cortese S, Castelnau P, Morcillo C, Roux S, Bonnet-Brilhault F. Psychostimulants for ADHD-like symptoms in individuals with autism spectrum disorders. Expert Rev Neurother. 2012;12(4):461-73. https://doi.org/10.1586/ern.12.23.

19. Rodrigues R, Lai MC, Beswick A, Gorman DA, Anagnostou E, Szatmari P, Anderson KK, Ameis SH. Practitioner review: pharmacological treatment of attention-deficit/hyperactivity disorder symptoms in children and youth with autism spectrum disorder: a systematic review and meta-analysis. J Child Psychol Psychiatry. 2021;62(6):680-700. https://doi.org/10.1111/jcpp.13305.

20. Lamberti M, Italiano D, Guerriero L, D’Amico G, Siracusano R, Ingrassia M, Germanò E, Calabrò MP, Spina E, Gagliano A. Evaluation of acute cardiovascular effects of immediate-release methylphenidate in children and adolescents with attention-deficit hyperactivity disorder. Neuropsychiatr Dis Treat. 2015;11:116974. https://doi.org/10.2147/NDT.S79866.
21. Arcieri R, Germinario EA, Bonati M, Masi G, Zuddas A, Vella S, Chiarotti F, Panei P, Italian Attention-Deficit/Hyperactivity Disorder Regional Reference Centers. Cardiovascular measures in children and adolescents with attention-deficit/hyperactivity disorder who are new users of methylphenidate and atomoxetine. J Child Adolesc Psychopharmacol. 2012;22(6):423-31. https:// doi.org/10.1089/cap.2012.0014.

22. Vitiello B, Elliott GR, Swanson JM, Arnold LE, Hechtman L, Abikoff H, Molina BSG, Wells K, Wigal T, Jensen PS, Greenhill LL, Kaltman JR, Severe JB, Odbert C, Hur K, Gibbons R. Blood pressure and heart rate in the Multimodal Treatment of Attention Deficit/Hyperactivity Disorder Study over 10 years. Am J Psychiatry. 2012;169:167-77. https://doi.org/10.1176/appi.ajp.2011. 10111705 .

23. Hammerness PG, Perrin JM, Shelley-Abrahamson R, Wilens TE. Cardiovascular risk of stimulant treatment in pediatric attentiondeficit/hyperactivity disorder: update and clinical recommendations. J Am Acad Child Adolesc Psychiat. 2011;50:978-90.

24. Hennissen L, Bakker MJ, Banaschewski T, Carucci S, Coghill D, Danckaerts M, Dittmann RW, Hollis C, Kovshoff H, McCarthy S, Nagy P, Sonuga-Barke E, Wong IC, Zuddas A, Rosenthal E, Buitelaar JK, ADDUCE consortium. Cardiovascular effects of stimulant and non-stimulant medication for children and adolescents with ADHD: a systematic review and meta-analysis of trials of methylphenidate, amphetamines and atomoxetine. CNS Drugs. 2017;31(3):199-215. https://doi.org/10.1007/s40263-017-0410-7.

25. Faraone SV, Po MD, Komolova M, Cortese S. Sleep-associated adverse events during methylphenidate treatment of attentiondeficit/hyperactivity disorder: a meta-analysis. J Clin Psychiatry. 2019;80(3): 18r12210. https://doi.org/10.4088/JCP.18r12210. 